\title{
A Transmissão da Cultura da Brincadeira: Algumas Possibilidades de Investigação
}

\author{
Fernando Augusto Ramos Pontes ${ }^{12}$ \\ Celina Maria Colino Magalhães \\ Universidade Federal do Pará
}

\begin{abstract}
Resumo
Este trabalho esboça possibilidades de investigar fatores relacionados à transmissão da cultura do brinquedo. A brincadeira pressupõe uma aprendizagem social, aprendem-se as formas, o vocabulário típico, os tipos de interações condizentes, as regras, o momento de enunciá-las etc. A investigação de tais categorias e dos fatores envolvidos em sua produção é importante para uma melhor descrição da brincadeira e da ocorrência de aprendizagem em situação natural e também para criar indicadores para a compreensão das relações entre os membros dos grupos de crianças, da socialização, da constituição do sujeito e da transmissão da cultura.

Palavras-chave: Brincadeiras; jogos; interação criança-criança; transmissão cultural.
\end{abstract}

The Transmission of Play Culture: Some Research Possibilities

\begin{abstract}
This article outlines possibilities of investigating factors related to the transmission of play culture. Play is actively implicated in social learning, where, among other things, routines, vocabulary, types of rules and a interactions are learned. We believe that a thorough investigation of these factors, as well as a study of these play-related categories are important. Not only because they provide opportunities for a complete description of play and occurrence of learning in a natural setting, but also because they serve as indicators for understanding the relationships between groups of children, their socialization, and involvement as agents of cultural transmission.

Keywords: Games; toys; child interaction; cultural transmission.
\end{abstract}

Brinquedo e criança são palavras que estão estreitamente associadas. Todas as sociedades reconhecem o brincar como parte da infância. Os primeiros registros desse reconhecimento, obtido por meio de escavações arqueológicas, advêm do período em que nossa espécie ainda tinha como modo de sobrevivência básico a caça e coleta (Frenzel, 1977). O mesmo não se pode dizer acerca das palavras "cultura" e "criança". Salvo algumas exceções, o fenômeno cultura foi freqüentemente tratado como uma propriedade do adulto. Quando se faz alusão ao termo patrimônio cultural, geralmente se remete a aspectos da cultura adulta como prédios, danças, comidas típicas, vestuário e artefatos artesanais.

Isso se deve, em parte, ao fato de ter perdurado por muito tempo, em algumas abordagens, uma visão adultocêntrica e futurista em relação ao desenvolvimento infantil. Carvalho e Beraldo (1989) afirmam que este tipo de visão impediu que se visse a riqueza das interações criançacriança, pois o que poderia uma criança incompetente oferecer a outra igualmente incompetente? Essas autoras

\footnotetext{
${ }^{1}$ Pesquisador bolsista do CNPq.

2 Endereço para correspondência: Av. Rodrigues de Farias, 16, 66095240 , Fone(s): 2769533; 211-1453, Fax: 211-1662. E-mail: farp@cpgp.ufpa.br
}

enfatizam o interesse pelo estudo das interações criançacriança, partindo do pressuposto de que elas são de alta prioridade motivacional para os sujeitos envolvidos.

O elo entre "cultura" e "criança" é claramente percebido nos jogos e brincadeiras tradicionais e populares, especialmente aquelas desenvolvidas em rua. A modalidade “jogo tradicional infantil”" possui características de anonimato, tradicionalidade, transmissão oral, conservação, mudança e universalidade (Kishimoto, 1993). Apesar de os jogos tradicionais caracterizarem uma cultura local (Friedmann, 1990), é interessante a existência de certos padrões lúdicos universais, mesmo observando-se diferenças regionais, como variações nas designações, e nas regras e suas formas de utilização.

A brincadeira de "cabra-cega" já era cultivada entre os romanos no século III a.C. com o nome de "murinda"; na Espanha tem o nome de "galinha cega"; na Alemanha de "vaca-cega"; nos Estados Unidos de "blindman's buff" e na França de "colinmaillard" (Medeiros, 1990). A peteca, usada no "jogo de peteca" em Belém, é conhecida, no mundo de língua inglesa, como "game of marble" e, em grande parte do Brasil, como jogo de "bola de gude". Apesar de momentos e espaços diferentes, a estrutura das regras é extremamente 
semelhante. Conservação, mudança e universalidade são palavras-chave para a compreensão desses jogos.

Piaget (1977) viu as regras do jogo de bola de gude como um fenômeno da moralidade, o que possibilitava o estudo do desenvolvimento moral da criança pela observação da maneira como ela lida com essas regras. Para tanto descreveu de forma minuciosa as regras dessa brincadeira em Neuchâtel, na Suíça. É surpreendente a semelhança entre algumas regras encontradas por Piaget e as encontradas em Belém no jogo de peteca ${ }^{3}$ (Pontes \& Galvão, 1992, 1997), e em outras regiões do Brasil (Neto, 1977).

É evidente o caráter dinâmico da manutenção de tais normas, o que parece ser um paradoxo, mas, como Laraia (1986) sustenta, qualquer sistema cultural está num contínuo processo de mudança, ou seja, a conservação é sempre algo relativo, depende da dimensão de tempo e do sistema cultural a ser considerado. É certo, entretanto, que o fenômeno cultural também pode mostrar uma estabilidade considerável no decorrer do tempo e no espaço (Cavalli-Sforza; Feldman, Chen \& Dornbush, 1982).

Pode-se interrogar: como, de criança a criança, de geração em geração, as regras e as formas de brincar são ensinadas e aprendidas? A impressão leiga é de que o jogar e o brincar são ensinados como normalmente os adultos ensinam a um outro adulto um jogo, de modo sistemático e diretivo. Ao ensinar-se uma nova modalidade de jogar baralho, por exemplo, utiliza-se de dicas verbais, sistemáticas, seqüenciais (por passos) e de exemplos: "o jogo inicia quando ...", "ganha quem ...".

Interessa para a psicologia social e do desenvolvimento (além da constatação da existência da brincadeira em si, das regras e estrutura semelhantes em várias gerações e localidades), saber quais os mecanismos que possibilitam a universalidade das brincadeiras tradicionais, ou seja, como as brincadeiras são repassadas de geração a geração de crianças? Quais formas de transmissão (de acordo com as concebidas por Cavalli-Sforza \& Feldman, 1981; segue discussão) são predominantes? Que modos de organização social permitem a transmissão? Quais são os elementos de análise a serem usados para obter uma visão coerente e sistemática da transmissão da brincadeira entre as crianças?

A brincadeira pressupõe uma aprendizagem social (Brougère, 1997). Aprendem-se as formas, o vocabulário típico, as regras e o seu momento de enunciá-las, as habilidades específicas requeridas para cada brinquedo,

\footnotetext{
${ }^{3}$ Para fins de contextualização regional, deve-se entender, no restante desse texto, que o termo "jogo de peteca" refere-se ao que, em algumas regiões do Brasil é conhecido como "jogo de bola de gude".
}

os tipos de interações condizentes etc. Acredita-se que a investigação dessas e de outras categorias de eventos seja importante não só para uma melhor descrição da brincadeira e da ocorrência de aprendizagem em situação natural, mas também para a compreensão dos processos de transmissão da cultura da brincadeira, assim como das relações entre os membros do grupo e do desenvolvimento infantil.

Recentemente, várias tentativas têm sido feitas na busca de modelos para a compreensão da transmissão e da evolução da cultura; destacam-se os trabalhos de CavalliSforza e Feldman (1981), Cavalli-Sforza, Feldman, Dornbusch e Chen (1983) e Baum (1999).

O termo transmissão cultural foi introduzido por CavalliSforza e Feldman (1981) como um paralelo à noção de transmissão biológica. Por analogia, a transmissão cultural permite a um grupo perpetuar uma característica nas gerações subseqüentes por meio de mecanismos de ensino e aprendizagem.

Para Cavalli-Sforza e colaboradores (1982), "a transmissão cultural é o processo de aquisição de comportamentos, atitudes ou tecnologias através de estampagem, condicionamento, imitação, ensino ativo e aprendizagem ou a combinação desses elementos" (p. 19). Nesse modelo, quando a transmissão ocorre dos pais para a criança, ela é denominada de vertical; quando é feita entre membros da mesma geração (adulto-adulto, criança-criança), denomina-se de horizontal, e é chamada oblíqua quando se dá entre não-parentes de gerações diferentes.

A partir do modelo comportamental, Baum (1999) identifica duas formas pelas quais os traços culturais adquiridos são transmitidos: a primeira pela imitação e a segunda por meio do seguimento de regras. Para este autor, na imitação existe uma cópia direta, provendo a base da aprendizagem operante. Por outro lado, a imitação aprendida é uma forma de comportamento controlado por regras, "as crianças aprendem o comportamento de seguir regras porque a transmissão de práticas sociais através do seguimento de regras é particularmente rápida.” (p. 265).

Tomasello, Kruger e Ratner (1993), em uma perspectiva teórica distinta da utilizada por Baum, salientam a importância de se discernir entre a aprendizagem social e a aprendizagem cultural. Para esses autores a aprendizagem social pode ser definida pelos mesmos critérios utilizados por Bandura (1986, conforme citado em Tomasello \& cols., 1993), o qual concebe que esta é uma forma de aprendizagem individual, influenciada de alguma maneira pelo ambiente social. No entanto, a natureza característica da espécie humana - de aprender a partir de um outro apresenta uma maneira qualitativamente diferente de ser; os aprendizes não estão com sua atenção voltados 
diretamente para a atividade do outro indivíduo, pelo contrário eles tentam ver a situação da forma que o outro vê. Esta aprendizagem, na qual o aprendiz tenta aprender não a partir do outro, mas através do outro, é denominada pelos autores de "aprendizagem cultural".

Tomasello e colaboradores (1993) distinguem três tipos de aprendizagem cultural: a aprendizagem imitativa, a aprendizagem instruída e a aprendizagem colaborativa. $\mathrm{Na}$ aprendizagem imitativa o aprendiz internaliza algo da estratégia comportamental do demonstrador, podendo ocorrer dentro ou fora do contexto pedagógico. Quando o ensino está envolvido no processo, pode ocorrer a aprendizagem instruída, essencialmente Vygotskyniana, na qual aprendizes internalizam as instruções e as usam subseqüentemente para auto-regular sua atenção, sua memória e outras funções cognitivas. A aprendizagem colaborativa não envolve a transmissão, no sentido clássico, do mais experiente para o aprendiz. Por definição, a situação consiste de pares que colaboram para construir algo novo e diferente do que a díade possuía antes de a interação iniciar. Para os autores, este processo realça o espírito inventivo e conduz à evolução cultural. Em uma minoria dos casos, a aprendizagem colaborativa pode contribuir para a manutenção de tradições culturais.

São evidentes as contribuições de tais modelos, tanto em termos heurísticos quanto na criação de um arcabouço teórico, o qual dá sentido às pesquisas da área e aumenta o interesse por estas, buscando principalmente pôr à prova tais modelos.

Apresentam-se aqui algumas reflexões acerca dos fatores correlacionados à transmissão da cultura da brincadeira, tentando-se esboçar alguns elementos teóricos e metodológicos que possam viabilizar uma aproximação do fenômeno.

\section{Unidades de análise}

A busca da compreensão dos mecanismos envolvidos na transmissão da cultura da brincadeira demanda desenvolvimento de unidades de análise. O modelo aqui enfocado leva em conta os seguintes elementos que se interinfluenciam (ver Figura 1): o grupo, a estrutura da brincadeira, comportamento do mais experiente com relação ao aprendiz e comportamento do aprendiz.
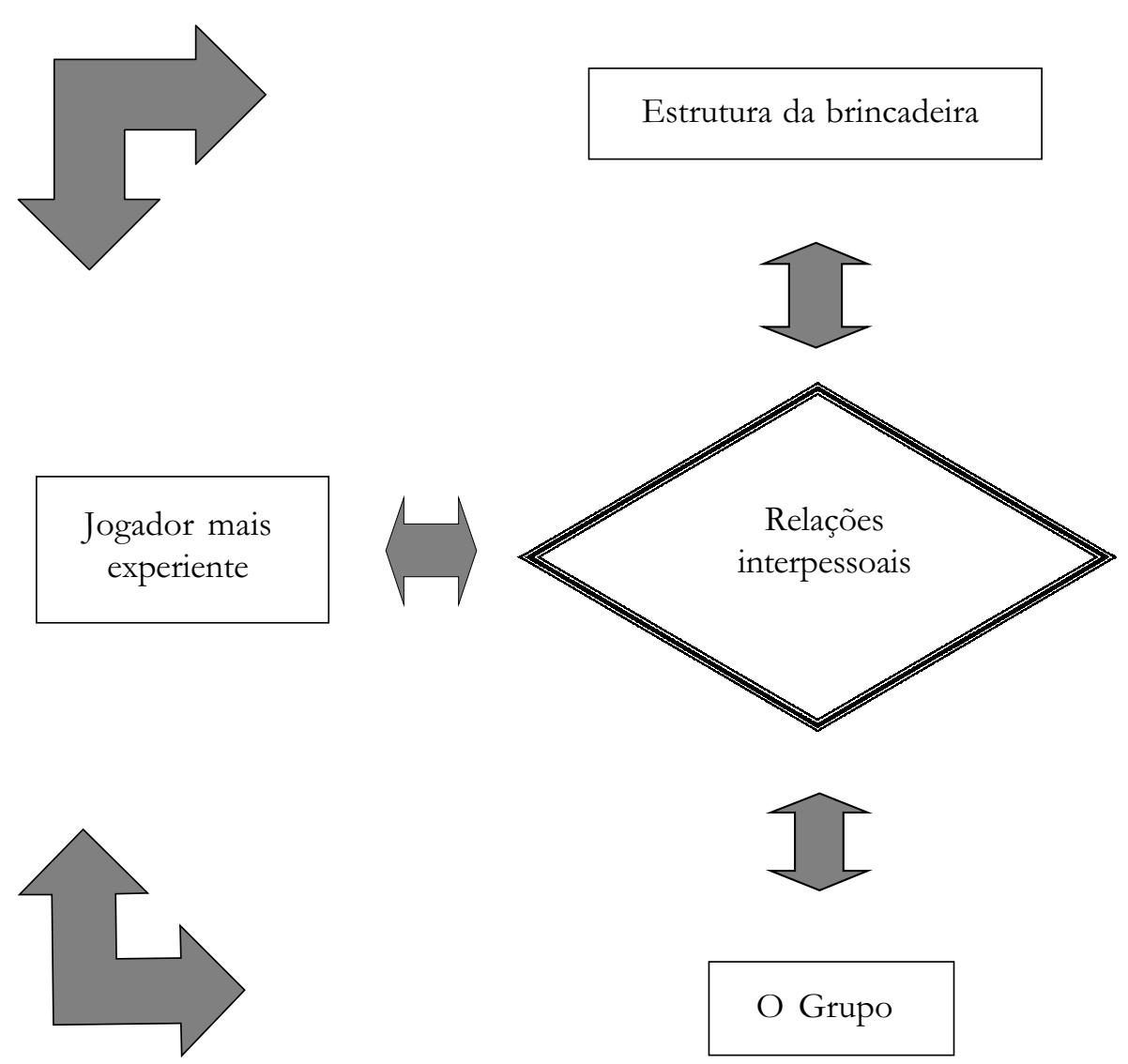
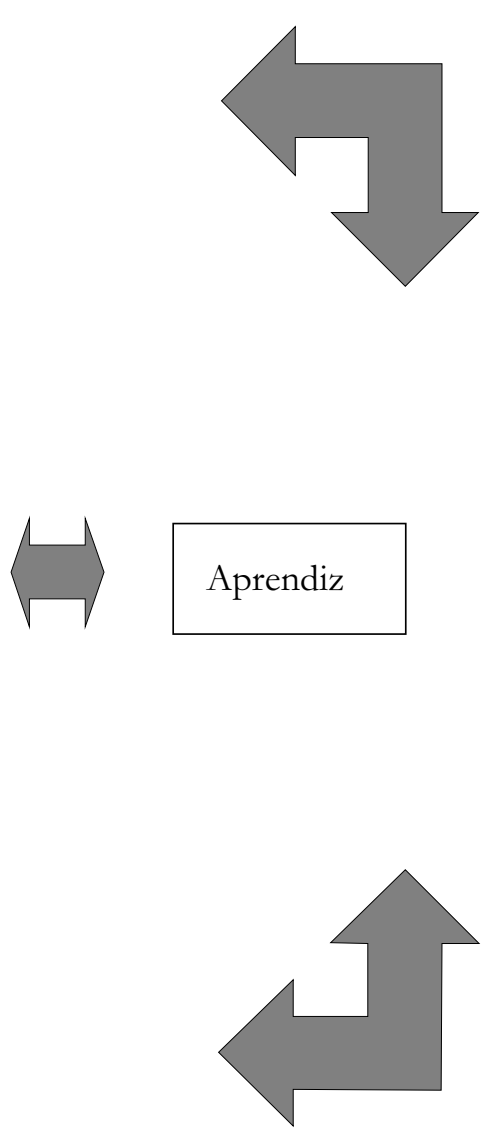

Figura 1. Elementos a serem considerados na análise da transmissão da cultura da brincadeira. 


\section{O Grupo}

Qualquer transmissão de um elemento cultural só pode ocorrer dentro de um contexto social. A cultura da brincadeira é um fenômeno de grupo. É só em um conjunto de sujeitos que mutuamente se regulam, com uma identificação própria e com um modo de organização típico, que uma brincadeira tradicional se mantém e é repassada. Nesse sentido, parte-se do pressuposto de que entender a organização social de um determinado grupo é um fator essencial para se estudar a transmissão da cultura.

No que diz respeito ao contexto social em que ocorre o processo de aprendizagem das brincadeiras tradicionais de rua, alguns indicadores podem ser discutidos a partir do estudo de Anjos, Silva, Santos, Pontes e Magalhães (2001). Neste trabalho foi investigada a percepção das crianças acerca dos referenciais de aprendizagem das brincadeiras de peteca e pipa. Dentre uma das questões feitas, foi perguntado aos brincantes com quem ele aprendeu a brincadeira. As respostas foram agrupadas em duas categorias: a) familiares adultos e b) sozinhos/em pares. Constatou-se nas duas brincadeiras, uma maioria significativa das respostas na categoria sozinho/em pares. Apesar de serem necessários estudos mais detalhados, tal resultado indica que o grupo de coetâneos é determinante na transmissão da cultura das brincadeiras investigadas. De acordo com as categorias de transmissão da cultura desenvolvidas por Cavalli-Sforza e Feldman (1981), acredita-se que a transmissão da cultura das brincadeiras de rua é essencialmente vertical (criança-criança). Levando em conta o nível de desenvolvimento cognitivo dos atores principais, a transferência de conhecimento se dá com baixo direcionamento. Deste modo então, são salientados dois processos principais de aprendizagem cultural indicado por Tomasello e colaboradores (1993): a aprendizagem imitativa e a aprendizagem colaborativa.

Os conceitos, os vocabulários e as habilidades são partilhados dentro de um grupo de praticantes de determinada brincadeira. Não se deve restringir, entretanto, o grupo aos que estritamente participam da brincadeira. Todo o entorno de sujeitos que "orbitam" no grupo de praticantes está de algum modo partilhando o evento.

A brincadeira de rua é um evento social que tem a propriedade de ser um pólo aglutinador de interações. Praticantes de determinada brincadeira tendem a atrair observadores, dentre os quais, estão sujeitos inexperientes ou menos habilidosos, aprendizes em potencial.

Esses observadores tendem a assumir diferentes papéis no grupo. Alguns assumem tarefas periféricas na brincadeira, uns comentam momentos do jogo e outros simplesmente observam passivamente. Pode-se considerar que todos, mesmo esses últimos, partilham o evento. Assim sendo, para fins de estudo da transmissão da cultura e, conseqüentemente, de configuração de um grupo, o fator proximidade física deve ser um dos critérios a serem considerados. Os observadores (ativos ou passivos) fazem parte do grupo, mesmo que não estejam precisamente participando da brincadeira em questão. Embora o modo de participação de cada sujeito no grupo seja categorizado de forma diferente, interessa, neste caso, mais o partilhar do evento do que a estrita atividade de brincar em si.

Essa forma de entender o contexto se aproxima do que Super e Harkness (1986) e Harkness e Super (1983) denominam de nicho desenvolvimental. Um dos três componentes do nicho desenvolvimental é o "contexto social e físico no qual a criança vive". O contexto social, formado pelas pessoas com as quais a criança interage, modela o comportamento social, as normas e os valores. Documentar a proximidade física de cada criança aos eventos sociais é um indicador do contexto de desenvolvimento, do contexto de aquisição de cultura.

A partilha de elementos culturais parece ser diferencialmente propiciada às crianças. Algumas brincadeiras são praticadas somente por determinados estratos etários e, de uma forma mais conspícua, sexualmente segregadas.

Levantamentos anteriores (Pontes, Galvão, Costa \& Rosa, 1985; Souza, 1999) têm indicado que o tamanho do grupo e a faixa etária dos praticantes parecem variar em função da brincadeira ou jogo. Dados recentes (Santos, Anjos, Silva, Pontes \& Magalhães, 2001) indicam que em algumas brincadeiras, como a peteca, existe uma variação um tanto ampla de faixa etária de praticantes (7-18 anos), no entanto, os grupos de jogo tendem a se organizar em faixas etárias um tanto estreitas (7-9 anos; 9-12 anos; 1215 anos e assim em diante).

Nas brincadeiras cujos grupos são de coetâneos, a contribuição para a aprendizagem de determinado elemento cultural seria um tanto mais gradual do que nas brincadeiras com participação de faixas etárias mais amplas, pela diferença menor de habilidade entre os participantes. Nos grupos onde existe maior amplitude de faixa etária dos participantes, tal fenômeno fica mais evidente, como é o caso, em Belém, dos grupos formados para brincar de papagaio (Santos \& cols., 2001).

Quanto à segregação por sexo, vários estudos (Archer, 1992; Beraldo, 1993; Bichara, 1994; Maccoby, 1988) indicam que, desde os três anos de idade, as crianças já demonstram preferência por parceiros do mesmo sexo, embora participem também de atividades em grupos mistos. Esta segregação se acentua na média infância (idade escolar).

No mesmo sentido, algumas brincadeiras são típicas de determinados gêneros. Em nossa cultura, pular corda, 
brincar de macaca (amarelinha) e de elástico ${ }^{4}$ são brincadeiras tipicamente de meninas, enquanto jogar peteca e empinar papagaio (pipa, pandorga, arraia, etc.) são tidas como brincadeiras de meninos. Tal tipificação, entretanto, parece estar se modificando. Dados recentes (Chagas \& cols., 2000) indicam uma maior segregação na pipa do que na peteca.

Por refletir mudanças culturais, a brincadeira de rua apresenta-se como um ótimo material para estudo de segregação sexual e de questões de gênero. Dados preliminares (Silva, Santos, Anjos, Pontes \& Magalhães, 2001) indicam segregação sexual ativa em determinadas brincadeiras, de modo a caracterizá-las como tipicamente de menino ou de menina, atribuindo geralmente um status inferior para o membro do sexo oposto que a pratique. Essa segregação leva a diferentes domínios da cultura da brincadeira e, conseqüentemente, a rotas diferenciadas de transmissão da cultura.

A descrição da organização do grupo, enfim, compreende o levantamento de aspectos da sua composição, como sexo, faixa etária, tamanho etc., e da rede de relações nele formada. Uma descrição que abranja esses dois conjuntos de características permitirá estabelecer um panorama dos sujeitos que partilham determinadas habilidades culturalmente adquiridas.

\section{A Estrutura da Brincadeira}

A estrutura de um jogo é definida a partir da interrelação entre elementos que determinam a sua natureza. Avedon e Sutton-Smith (1971) combinando o trabalho de matemáticos e estudiosos do comportamento, identificaram nove elementos estruturais nos jogos: propósito ou razão, procedimentos de ação, regras que governam a ação número de jogadores requeridos, papéis dos participantes, habilidades e qualificação, padrões de interações dos participantes, cenário físico e ambiente necessário e equipamento para a sua prática.

Para fins da transmissão da cultura da brincadeira, além de atentar para os elementos acima descritos, novos elementos devem ser considerados: variações ou formas intermediárias, ou seja, como a brincadeira é apresentada, de modo a facilitar ou dificultar a participação de sujeitos. O desempenho das habilidades exigidas pode ser atingido

\footnotetext{
${ }^{4} \mathrm{O}$ elástico é uma brincadeira que tem como objetivo final conseguir executar todos os saltos sem errar. Dois dos brincantes ficam em pé, frente a frente, colocam o elástico em volta dos tornozelos, mantendo os pés juntos, formando um retângulo. Um terceiro brincante terá que realizar uma seqüência de saltos com dificuldades progressivas. Usam-se basicamente os membros inferiores (pernas e pés) para pular dentro, sobre e para fora do elástico e, ocasionalmente, utilizam-se os membros superiores (braços e mão) com função de apoio.
}

gradualmente ou aprendido pelo domínio de formas de complexidade gradualmente maiores. Em várias brincadeiras existem formas verbalmente codificadas de participar que são mais amenas nas sanções ou nas habilidades exigidas por seus praticantes, que são genericamente qualificadas como "fáceis", por meio de expressões como "café com leite, "neném", "do bem" etc.

No elástico, existe uma forma de o participante brincar que é menos rigorosa e permite a opção de entrar em qualquer fase da brincadeira. Denomina-se "anjinho" a criança que participa da brincadeira desse modo. O "anjinho" só entra na brincadeira com a anuência de algum dos participantes maiores, não é obrigado a jogar todas as seqüências e, mesmo que erre, não sai do jogo. Ele, entretanto, não opta pelas fases, deve apenas imitar o participante "tutor". Os anjinhos são geralmente as crianças aprendizes.

Uma outra maneira de se penetrar gradualmente na cultura da brincadeira se dá pelo uso de algumas formas adaptadas para as crianças com menos habilidades ou posses, como da curica para o papagaio ${ }^{5}$. Portanto, em algumas brincadeiras, a forma culturalmente dada está organizada de maneira que a criança penetre gradativamente nos aspectos específicos de sua cultura, em que a exigência e os materiais dispostos são diferentes em função do grau de habilidade da criança.

Uma discussão mais detalhada deste elemento de análise pode ser encontrada em Pontes e Magalhães (2002).

\section{O Mais Experiente e o Aprendiz}

Como a brincadeira implica uma aprendizagem sociocultural, evidenciam-se dois atores principais que devem se tornar um foco prioritário de análise: o mais experiente e o aprendiz.

Jogos de sujeitos mais experientes são mais complexos e mais avançados do que os de crianças iniciantes e representam, uma forma mais elaborada da cultura da brincadeira (Pontes \& Galvão, 1997).

Dificilmente um grupo apresenta entre os seus sujeitos o mesmo nível de habilidade. Levando em conta que os

\footnotetext{
${ }^{5}$ A curica é feita geralmente de papel de caderno, pode ter tala ou não; caso tenha tala, esta é de paneiro, por ser mais fina, e é enfiada na horizontal e vertical perfurando o papel, sua principal função é armar o papel, quando a curica fica muito mole. Uma folha de caderno é dobrada ao meio e recortada com a mão, de tal maneira que o miolo da folha fica sendo o corpo da curica e a tira de papel retirada das bordas, o rabo. É empinada por crianças com idade entre 2 e 5 anos, com poucos metros de linha. Geralmente é produzida pelas próprias crianças. O papagaio propriamente dito é feito de papel de seda, com o cruzamento de duas talas de miriti horizontais maiores e uma vertical. As duas horizontais são dispostas paralelamente. Rabo é feito de tiras de pano, empinado mais por adultos.
} 
sujeitos mais experientes organizam, distribuem papéis em uma determinada brincadeira e apresentam, no geral, uma postura mais ativa no grupo, pode-se dizer que a aprendizagem do iniciante depende, em parte, das oportunidades proporcionadas pela criança mais hábil. Uma parte do contato com a cultura mais elaborada da brincadeira depende então do comportamento do mais experiente, como uma certa tutoria.

A forma como o mais experiente irá lidar com o aprendiz pode ou não facilitar o processo de aprendizagem de determinadas habilidades da brincadeira. É certo que deve ser relativizado o "altruísmo" do mais experiente em função do aprendiz, pois geralmente este se comporta de modo a auxiliar aquele em algumas tarefas, essenciais ou não, da brincadeira. Um exemplo característico ocorre no momento de empinar o papagaio. Empinar o papagaio, ou seja, colocar o papagaio no ar, é mais fácil se alguém ajudar o empinador, levando o papagaio a uma certa distância para que o empinador possa, por meio de puxões na linha, atingir seu objetivo. Certamente o sujeito que leva o papagaio dispõe de alguns privilégios em função de sua ajuda, como poder, em determinados momentos, pegar na linha do papagaio e fazer manobras no ar (dar cabeçadas).

As oportunidades proporcionadas ao aprendiz podem, como já visto, estar previstas em algumas brincadeiras, no entanto, elas se realizam efetivamente quando as crianças mais hábeis assim o permitem. Nesse sentido, verifica-se a assimetria de papéis e variáveis relacionais como um fator presente no fenômeno de transmissão de cultura.

Por outro lado, os aprendizes tendem a orbitar nas brincadeiras, e quando não participam ativamente são essencialmente observadores. Como observadores, colocam-se na condição de ativos ou passivos. Observadores ativos diferenciam-se dos passivos por assumirem papéis periféricos na brincadeira (como o "gandula" no futebol). É curioso observar que, em dados recentes (material não-publicado), foram registrados poucos casos de crianças aprendizes fazendo perguntas ou pedindo esclarecimento sob determinadas situações.

De acordo com as características do ensino informal (Greenfield \& Lave, 1982, conforme citados em Segall, Dasen, Berry \& Poortinga, 1990), no que se refere à relação entre criança experiente e aprendiz, o sistema de transmissão de conhecimentos via cultura da brincadeira parece, em alguns casos, assemelhar-se à aprendizagem dos velhos ofícios, em que a forma de pagar pela oportunidade de aprender é dada por meio do trabalho. No geral, a posição assumida pelo experiente na dinâmica do jogo tende a ser mais ativa, dando direção à brincadeira, arbitrando, indicando erros etc, enquanto a do aprendiz tende a ser mais passiva, observando, jogando, esperando decisão, torcendo etc. Quando se considera, entretanto, a dinâmica da apreensão da cultura, a postura passiva do jogador menos experiente revela-se como parte de uma estratégia ativa.

A análise da relação diádica aqui exemplificada (experiente - aprendiz) é apenas um recorte que facilmente pode ser observado. As nuanças de outras relações (aprendiz aprendiz, experiente - experiente) e, conseqüentemente, das diferenças de níveis de cada uma dessas categorias certamente devem também denotar outros aspectos relevantes para compreensão da transmissão da cultura. De fato, o essencial é investigar os papéis de cada criança no grupo e, desse modo, revelar um pouco acerca da transmissão de conhecimento e habilidades culturalmente adquiridas.

\section{Considerações Finais}

\section{O Ponto de Partida e o Outro Lado da Moeda}

A brincadeira de rua é um fenômeno paradigmático do estudo da organização social de crianças e da cultura infantil. $\mathrm{O}$ estudo de brincadeiras tradicionais possibilita a investigação de um fenômeno infantil "espontâneo", sem o planejamento adulto e sem o recurso da escrita. Como assinalaram Opie e Opie (1976): "Nos jogos tradicionais de rua as crianças se engajam em regras testadas por séculos, que são passadas de criança para criança sem nenhuma referência à escrita, parlamento ou a alguma propriedade adulta" (p. 40). Mesmo em situações precárias de sobrevivência, as crianças na rua não se apresentam como desprivilegiadas ou carentes, antes, se mostram como seres humanos, exercendo as capacidades humanas de apropriação e transmissão de práticas culturais.

Tais considerações levam ao ponto de partida deste artigo. Entretanto, a ênfase no processo de transmissão só apresenta um lado da moeda, que, por questão prática, assume-se como um referencial inicial de reflexão. É evidente que a cultura adquirida não é uma cópia exata da cultura transmitida. As crianças, em suas interações, modificam a cultura. A sua transmissão não é somente uma repassagem, é uma reinvenção. Como salientam Tomasello e colaboradores (1993), na aprendizagem colaborativa os pares que constroem algo novo diferente do que a díade possuía antes da interação iniciar.

É dentro do grupo que ocorrem tanto a uniformidade e a constância como as variações e as novidades. É esse outro lado da moeda que apresenta os maiores desafios e riquezas a serem investigadas, ou seja, compreender nas relações entre os membros do grupo quais são os fatores envolvidos na manutenção, na variação, na novidade, no surgimento e desaparecimento dos rituais, na instauração e revogação das regras.

Psicologia: Reflexão e Crítica, 2003, 16(1), pp. 117-124 
Tradicionalmente, a psicologia do desenvolvimento tendeu a estudar a criança fora de seu contexto sociocultural, enquanto a antropologia cultural tendeu a enfatizar o contexto cultural em si e um adulto já socializado (Segall \& cols., 1990). O desafio está em saber lidar de forma adequada com as interfaces entre esses dois campos do conhecimento. A transmissão da cultura da brincadeira não se apresenta como um tema específico de determinada disciplina do conhecimento. Propõe-se, aqui, uma visão integradora e transdisciplinar. Da antropologia à psicologia, várias perspectivas poderiam ser abordadas.

É evidente que os vieses de cada pesquisador direcionam o recorte do fenômeno estudado, de modo que respostas a uma determinada questão de uma disciplina fiquem mais evidentes quando investigadas do ponto de vista de outra. A transmissão da cultura da brincadeira deve ser estudada não só a partir dos processos de aprendizagem, socialização e constituição do sujeito, já que no grupo de brincadeira estão presentes todos os elementos de uma sociedade: os rituais, as regras, as sanções, as formas de se esquivar das sanções, etc. A revelação necessária deste submundo (sem nenhum sentido pejorativo) exige a perspectiva dos estudos culturais. Crianças não são somente criadas, crianças se criam, crianças criam cultura.

\section{Referências}

Anjos, N. D. dos, Silva, S. D. B. da, Santos, J. de M. C., Pontes, F. A. R. \& Magalhães, C. M. C. (2001). Relatos dos brincantes de rua: Uma análise do referencial de aprendizagem e transmissão da cultura [Resumos]. Em Anais do II Congresso Norte-Nordeste de Psicologia. [CD rom].

Archer, J. (1992). Childhood gender roles: Social context and organization. Em H. McGurk (Org.), Childhood social development structure and development (pp. 31-61). Hillssdale: Lawrence Erlbaum.

Avedon, E. M. \& Sutton-Smith, B. (1971). The study of games. New York: John Wiley \& Sons.

Baum, W. M. (1999). Compreendendo o behaviorismo: Ciência, comportamento e cultura. Porto Alegre: Artmed.

Beraldo, K. E. A. (1993). Percepção de crianças de 5 a 10 anos em relação a diferenças de gênero de brincadeiras. Dissertação de Mestrado não-publicada, Curso de Pós-Graduação em Psicologia, Instituto de Psicologia, Universidade de São Paulo. São Paulo, SP

Bichara, I. D. (1994). Um estudo etológico da brincadeira de faz-de-conta em crianças de 2 a 7 anos. Tese de Doutorado não-publicada, Curso de PósGraduação em Psicologia, Instituto de Psicologia, Universidade de São Paulo. São Paulo, SP.

Brougère, G. (1997). Brinquedo e cultura. São Paulo: Cortez.

Carvalho, A. M. A. \& Beraldo, K. E. (1989). A interação criança-criança: Ressurgimento de uma área de pesquisa e suas perspectivas. Cadernos de Pesquisa, 71, 55-61.

Cavalli-Sforza, L. L. \& Feldman, M. W. (1981). Cultural transmission and evolution: A quantitative approach. Princeton, New York: Princeton University Press.

Cavalli-Sforza, L. L., Feldman, M. W., Chen, K. H. \& Dornbusch, S. M. (1982). Theory and observation in cultural transmission. Science, 218, $19-27$.
Cavalli-Sforza, L. L., Feldman, M. W., Dornbusch, S. M. \& Chen, K. H. (1983). Anthropology and cultural transmission. Nature, 304, 124.

Chagas, C. A. M., Santos, J. de M. C., Anjos, N. D. dos, Silva, S. D. B. da, Pontes, F. A. R. \& Magalhães, C. M. C. (2000). Formação de grupo e segregação sexual em brincadeiras de rua [Resumos]. Em Anais de Etologia, 18, 176.

Frenzel, R. M. (1977). Jugando. Mexico: Extemporâneos.

Friedmann, A. (1990). Jogos tradicionais na cidade de São Paulo: Recuperação e análise de sua função educacional. Dissertação de Mestrado não-publicada, Universidade Estadual de Campinas. Campinas, SP.

Harkness S. \& Super, C. M. (1983). The cultural construction of child development. Ethos, 11, 221-231.

Kishimoto, T. M. (1993). Jogos tradicionais infantis: O jogo, a criança e a educação. Petrópolis: RJ, Vozes.

Laraia, R. de B. (1986). Cultura: Um conceito antropológico. Rio de Janeiro: Zahar.

Maccoby, E. E. (1988). Gender as a social category. Developmental Psychology, 24, 55-765.

Medeiros, E. B. M. (1990). Brincadeiras e brinquedos como manifestação cultural. Cadernos do EDM: Comunicaçōes \& Debates, 2, 132-140.

Neto, S. J. (1977). O jogo de bolinhas de gude. Cadernos do folclore. Brasília: MEC.

Opie, I. \& Opie, P. (1976). Street games: Coounting-out and chasing. Em J. S. Bruner, A. Jolly \& K. Sylva (Org), Play: Its role in development and evolution (pp. 395-412). New York: Peguin.

Piaget, J. (1977). O julgamento moral da criança (E. Lenardon, Trad.). São Paulo: Mestre Jou. (Origina1 publicado em 1932)

Pontes, F. A. R., Galvão, O. F., Costa, F. A. \& Rosa, M. C. (1985). Levantamento por observação das atividades exercidas pelas crianças em ambiente interno e externo com vistas a subsidiar a elaboração de um currículo e das atividades de uma pré-escola comunitária. Em Programa e Resumos da XV Reunião Anual de Psicologia de Ribeirão Preto. Ribeirão Preto, São Paulo (p. 40).

Pontes, F. A. R. \& Galvão, O. F. (1992). Estudo descritivo das regras do jogo de peteca (bola de gude). Boletim de Psicologia, Sociedade de Psicologia de São Paulo, 42(96/97), 79-88.

Pontes, F. A. R. \& Galvão, O. F. (1997). Desenvolvimento do seguimento de regras no jogo de peteca (bola de gude). Psicologia: Teoria e Pesquisa, 42, 79-88.

Pontes, F. A. R. \& Magalhães, C. M. C. (2002). A estrutura da brincadeira e a regulação das relações. Psicologia: Teoria e Pesquisa, 18, 213-220.

Santos, J. de M. C., Anjos, N. D. dos, Silva, S. D. B. da, Pontes, F. A. R. \& Magalhães, C. M. C. (2001). Uma análise da configuração dos brincantes de peteca (bola de gude) e pipa. [ Resumos]. Em Anais do II Congresso Norte-Nordeste de Psicologia.[CD rom].

Segall, M. H., Dasen, P. R., Berry, J. W. \& Poortinga, Y. H. (1990). Human behavior in global perspective: An introduction to cross-cultural psychology. USA: Pregamon Press

Silva, S. D. B. da, Santos, J. de M. C., Anjos, N. D. dos, Pontes, F. A. R. \& Magalhães, C. M. (2001). Impressões de meninos sobre a participação de meninas em duas brincadeiras tipicamente masculinas: peteca (bola de gude) e pipa. [Resumos]. Em Anais do II Congresso NorteNordeste de Psicologia [CD rom].

Souza, A. R. (1999). Resolução de conflitos entre crianças em brincadeiras de rua. Dissertação de Mestrado não-publicada, Curso de Pós-Graduação em Psicologia: Teoria e Pesquisa do Comportamento, Universidade Federal do Pará. Belém, PA.

Super, C. \& Harkness, S. (1986). The developmental niche: A conceptualization at the interface of society and the individual. International Journal of Behavioral Development, 9, 545-570.

Tomasello, M., Kruger, A. C. \& Ratner, H. .H. (1993). Cultural learning. Behavioral and Brain Sciences, 16, 495-552. 
124 Fernando Augusto Ramos Pontes \& Celina Maria Colino Magalhães

Recebido: 10/08/2001

$1^{a}$ revisão: 07/01/2002

Última revisão: 22/08/2002

Aceite final: 27/08/2002

Sobre os autores

Fernando Augusto Ramos Pontes é Doutor em Psicologia pela Universidade de São Paulo. É Professor adjunto do Departamento de Psicologia Experimental da Universidade Federal do Pará. É pesquisador bolsista do CNPq.

Celina Maria Colino Magalhães é Doutora em Psicologia pela Universidade de São Paulo. É Professora adjunta do Departamento de Psicologia Experimental da Universidade Federal do Pará. 